\title{
ON THE COMMUTATIVITY OF TOEPLITZ OPERATORS WITH HARMONIC SYMBOLS
}

\author{
HASHEM AL SABI AND ISSAM LOUHICHI
}

Abstract. In this paper we prove that if the polar decomposition of a symbol $f$ is truncated above, i.e., $f\left(r e^{i \theta}\right)=\sum_{k=-\infty}^{N} e^{i k \theta} f_{k}(r)$ where the $f_{k}$ 's are radial functions, and if the associated Toeplitz operator $T_{f}$ commutes with $T_{z^{2}+\bar{z}^{2}}$, then $T_{f}=Q\left(T_{z^{2}+\bar{z}^{2}}\right)$ where $Q$ is a polynomial of degree at most 1 .

Mathematics subject classification (2010): Primary 47B35, Secondary 47B38.

Keywords and phrases: Toeplitz operator, quasihomogeneous symbol, Mellin transform.

\section{REFERENCES}

[1] S. AXLER AND Ž. ČUČKOviĆ, Commuting Toeplitz operators with harmonic symbols, Integral Equations and Operator Theory 14, 1-12 (1991).

[2] S. AXler, Ž. ČUČKović, AND N. V. RaO, Commutants of analytic Toeplitz operators on the Bergman space, Proc. Amer. Math. Soc. 128, 1951-1953 (2000).

[3] A. BRown And P. R. Halmos, Algebraic properties of Toeplitz operators, J. Reine Angew. Math. 123 (1964), 89-102.

[4] H. Hedenmalm, B. Korenblum, And K. Zhu, Theory of Bergman spaces, Springer Verlag, New York, 2000.

[5] I. Lounichi, Powers and roots of Toeplitz operators, Proc. Amer. Math. Soc. 135: 5 (2007), 14651475.

[6] I. Louhichi, N. V. Rao, A. Yousef, Two questions on the theory of Toeplitz operators on the Bergman space, Complex Anal. Oper. Theory 3 (2009), no. 4, 881-889.

[7] A. Youssef, Two Problems in the Theory of Toeplitz. Operators on the Bergman Space, 2009, Doctor of Philosophy, University of Toledo, Mathematics. 